\title{
Advantages and limits of adsorption sampling for physico-chemical measurements of odorous compounds
}

\author{
J.-M. Guillot ${ }^{1 *}$, B. Fernandez ${ }^{1}$, P. Le Cloirec ${ }^{2}$ \\ ${ }^{1}$ École des Mines d'Alès, Laboratoire Génie de l'Environnement Industriel, 6 avenue de Clavières, 30319 Alès Cedex, France \\ ${ }^{2}$ École des Mines de Nantes, Département Systèmes Énergétiques et Environnement, 4 rue Alfred Kastler, BP 20722, \\ 44307 Nantes Cedex 3, France
}

\begin{abstract}
Adsorption of organic odorous compounds on different sorbents was studied as a sampling technique. Performances and limits of such a preconcentration method were determined by using synthetic atmospheres of odorous pollutants under different conditions and Tenax TA and Carboxen 564 as sorbents. Flow rate, temperature and concentration influences on sampling were tested independently and combined. The influence of humidity on sampling and the efficiency of dryers were also studied. Sample concentration and recuperation by thermal desorption was developed and analysis was performed by GC/MS.
\end{abstract}

available to retain quantitatively and later to release all volatile organic pollutants. So, the choice of a sorbent is very important to preserve sample integrity. In order to trap odorous compounds with very different properties, multi-bed sorbents seem to be useful [7] and therefore two sorbents: a carbon molecular sieve, Carboxen 564, and a porous polymer, Tenax TA were used alone or combined in this study. In a two-bed sorbent, Tenax TA is placed first to trap heavy molecules and Carboxen 564 is put secondly to trap smaller compounds.

The influence of several factors such as temperature, concentration, flow rate and humidity should be considered on adsorption process [8]. In some cases, field sampling depends on weather conditions. For example, $90 \%$ relative humidity (r.h.) at $25{ }^{\circ} \mathrm{C}$ refers to a water vapour concentration of $21000 \mathrm{mg} \cdot \mathrm{m}^{-3}$. Thus, when air is collected during rain or high atmospheric humidity, water may be the only major compound retained on sorbent material because of organic compound levels which are typically lower [9]. Presence of water in the collected sample is also unacceptable because it presents a major problem in the subsequent GC/MS analysis. There is a gradual desactivation of the chromatographic column after repeated analysis and injection of water can cause failure when using mass spectrometry. In humid conditions, Tenax TA and Carboxen 564 were studied. Several methods have also been developed to remove water vapour from the sample stream before reaching the sorbent tube, involving absorption with hygroscopic salts [10-11] or Nafion dryers [12], but water removal leads to losses of polar compounds. Another approach is to trap the water of the effluent by condensation at low temperatures [13]. However, their suitability for the whole set of compounds is still controversial. Thus, at low concentrations, losses of one or more components are usually observed.

This paper deals with conditions of preconcentration, by adsorption step, of odorous compounds. First of all, the influence of some operating parameters alone is studied. Then, the study of combined influence of these parameters, with experimental methodology [14], is carried out to find out good conditions of trapping. In order to minimise the interaction of humidity, drying agents are tested to remove water during trace enrichment of air samples. 


\section{Materials}

\section{Selected odorous compounds}

Some standard molecules were selected as representative odorous compounds among the main odorous families of organics like oxygenated, sulphur and nitrogen derivatives. Other compounds often used as solvents (aliphatic, aromatic or chlorinated hydrocarbons) were added. All were high purity compounds ( $\geq 99 \%$ ) coming from Aldrich-Fluka. Some of their physico-chemical characteristics are reported in table I.

\section{Selected sorbents}

Two sorbents, purchased from Supelco, were selected: a porous polymer, Tenax TA and a carbon molecular sieve, Carboxen 564. Some properties of these sorbents are given in table II.

\section{Experimental set-up}

A liquid mixture of the probe substances was set into a $5 \mathrm{~mL}$ syringe. The gas mixture was generated by an automatic syringe dispenser via continuous injection of the solution, into a reconstituted air flow. This air can be humidified (40, 70 or $>90 \%$ relative humidity) by the connection of bubblers containing deionised water at a controlled temperature. A RHT 100 Ebro hygrometer provided data on relative humidity. The flow rate in the dilution stream is measured with Platon flowmeters. The concentration for each compound was approximately $10 \mathrm{mg} \cdot \mathrm{m}^{-3}$. The flow rate through sorption tubes was adjusted by controlling an alpha-1 Ametek pump. The device used for the generation of polluted atmosphere is shown in figure 1.
Table I. Some characteristics of selected odorous compounds.

\begin{tabular}{lccc}
\hline Compound & $\begin{array}{c}\text { Boiling point } \\
\left({ }^{\circ} \mathrm{C}\right)\end{array}$ & $\begin{array}{c}\text { Molecular weight } \\
\left(\mathrm{g} . \mathrm{mol}^{-1}\right)\end{array}$ & $\begin{array}{c}\text { Density } \\
\text { at } 20{ }^{\circ} \mathrm{C}\end{array}$ \\
\hline Ethanethiol & 35 & 62.13 & 0.839 \\
Dimethylsulphide & 38 & 62.13 & 0.847 \\
Dimethyldisulphide & 109 & 94.19 & 1.063 \\
Propylamine & 47 & 59.11 & 0.716 \\
Diethylamine & 55 & 73.14 & 0.707 \\
Triethylamine & 89 & 101.19 & 0.726 \\
Methanol & 65 & 32.04 & 0.791 \\
Acetone & 56 & 58.08 & 0.789 \\
Ethyl acetate & 77 & 88.11 & 0.900 \\
Dichloromethane & 40 & 84.93 & 1.325 \\
Hexane & 69 & 86.18 & 0.660 \\
Toluene & 111 & 92.14 & 0.867 \\
\hline
\end{tabular}

Table II. Some physico-chemical properties of the two selected sorbents.

\begin{tabular}{lrcc}
\hline Sorbent & $\begin{array}{c}\text { Specific area } \\
\left(\mathrm{m}^{2} \cdot \mathrm{g}^{-1}\right)\end{array}$ & $\begin{array}{c}\text { Size } \\
(\mathrm{mm})\end{array}$ & $\begin{array}{c}\text { Temperature } \\
\text { limit of } \\
\text { utilization }\left({ }^{\circ} \mathrm{C}\right)\end{array}$ \\
\hline Carboxen 564 & 400 & $0.40 / 0.84$ & 400 \\
Tenax TA & 19 & $0.18 / 0.25$ & 350 \\
\hline
\end{tabular}

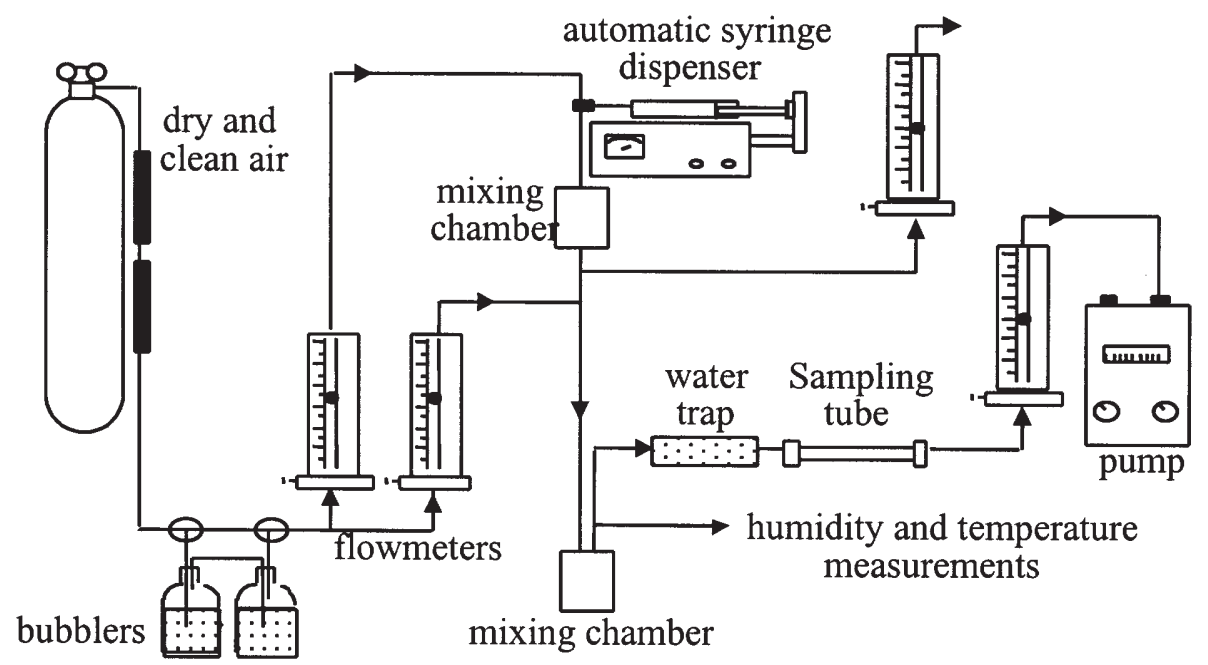

Figure 1. Device of atmosphere generation and tube sampling. 


\section{Preparation of sorbent tubes}

The sorption tubes are $89 \mathrm{~mm}$ length $\times 4 \mathrm{~mm}$ i.d. stainless steel tubes designed for the automatic thermal desorber ATD 400 from Perkin Elmer. They were filled with $0.3 \mathrm{~g}$ of Tenax-TA or $0.3 \mathrm{~g}$ Carboxen-564. Glass tubes, easier to packed, contained $50 \%(0.15 \mathrm{~g})$ of each adsorbent with Tenax TA as the first sorbent bed (Fig. 2). Small plugs of silanized glass wool held sorbents in place. The tubes were conditioned before each use by heating at $275{ }^{\circ} \mathrm{C}$ for $1 \mathrm{~h}$ with a helium flow of $20 \mathrm{~mL} \cdot \mathrm{min}^{-1}$.

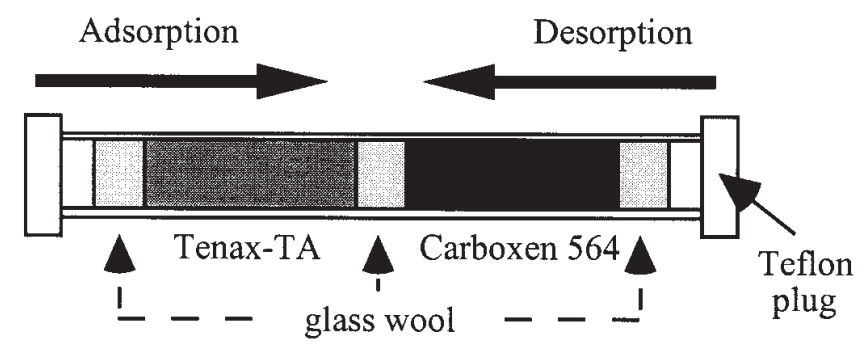

Figure 2. An example of sampling cartridge.

\section{Methods}

\section{Independent influence of operating conditions on sampling and breakthrough volume}

The influence of flow rate, temperature and concentration was tested independently. For these three experiments, sampling was realised on a cartridge composed of Tenax TA/Carboxen 564.

\section{Influence of flow rate on quantitative sampling}

Different flow rates were tested up to $2.2 \mathrm{~L} \cdot \mathrm{min}^{-1}$ with an atmosphere containing acetone at $0.1 \mathrm{mg} \cdot \mathrm{m}^{-3}$, at $25{ }^{\circ} \mathrm{C}$. Sampling time on the cartridge was adjusted to analyse the same volume of two litres.

\section{Influence of temperature on breakthrough volume}

Three gaseous mixtures were generated: sulphur compounds (ethanethiol, dimethylsulphide and dimethyldisulphide), amines (propylamine, diethylamine and triethylamine) and oxygenated compounds (methanol, acetone and ethyl acetate). The concentration of each compound in mixtures was $0.5 \mathrm{mg} . \mathrm{m}^{-3}$ for sulphur compounds and $5 \mathrm{mg} \cdot \mathrm{m}^{-3}$ for amines and oxygenated compounds. Sampling was carried out at $200 \mathrm{~mL} \cdot \mathrm{min}^{-1}$ on Tenax TA/Carboxen 564.

\section{Influence of concentration on breakthrough volume}

The influence of concentration (in a range of 0.1 to 20.4 mg. $\mathrm{m}^{-3}$ ) was studied with different atmospheres composed of an equimolar mixture of five compounds : acetone, ethanol, ethyl acetate, dimethysulphide and diethylamine. Sampling was carried out at a temperature of $25^{\circ} \mathrm{C}$ and a flow rate of $200 \mathrm{~mL} \cdot \mathrm{min}^{-1}$.

\section{Combined influence of flow rate, temperature and concentration}

In order to approach influence of several factors and their interactions, the methodology of experimental design was used [14]. It allows to quantify the relative influence of the chosen factors (flow rate, temperature and concentration) on a response (quantity of adsorbed components on a Tenax TA - Carboxen 564 sampling tube).

For this study, a complete factorial design $2^{3}$, corresponding to 8 experiments, was carried out. The variation field of the three factors is given in table III, by symbolic low and high limits of the factors (levels -1 and +1 respectively).

The experiments were carried out, in triplicate, with synthetic atmospheres containing acetone, dimethyldisulphide, propylamine, dichloromethane, hexane and toluene. The two concentrations were obtained by using the device described in figure 1 and temperatures were regulated with heating line around the sampling tube.

All calculations were performed with the NEMROD 3.0 software, (New Efficient Methodology for Research using Optimal Design), developed by the "Laboratoire de Prospective Réactionnelle et d'Analyse de l'Information", Aix-Marseille University (France).

Table III. Experimental field.

\begin{tabular}{lccc}
\hline Factors & Symbol & level -1 & level +1 \\
\hline Flow rate $\left(\mathrm{mL} \cdot \mathrm{min}^{-1}\right)$ & $\mathrm{F}$ & 100 & 200 \\
Temperature $\left({ }^{\circ} \mathrm{C}\right)$ & $\mathrm{T}$ & 10 & 30 \\
Concentration $\left(\mathrm{mg} \cdot \mathrm{m}^{-3}\right)$ & $\mathrm{C}$ & 0.5 & 5 \\
\hline
\end{tabular}

\section{Modification of adsorption with humidity}

For the study of the influence of humidity, a mixture of four compounds (acetone, ethanethiol, triethylamine and hexane) depending on different chemical families was chosen. The influence of humidity was compared with cartridge containing $0.3 \mathrm{~g}$ of Tenax TA or Carboxen 564.

\section{Test to remove humidity before the sampling step}

The efficiency of drying agents $(5 \mathrm{~g})$ such as sodium carbonate, magnesium sulphate and calcium chloride was tested. A glass cold trap (50 cm, $6 \mathrm{~mm}$-i.d.) in coils placed in crushed ice was also used to try to retain water. The agents were purified by flushing packed cartridges $2 \mathrm{~h}$ with helium.

A series of analyses were performed to compare the response of individual sorbents (Tenax TA and Carboxen 564) with different relative humidity values of the 
polluted air mixture sampled. The testing on sorbent tubes was conducted using a $4 \mathrm{~L}$ sampling volume collected at $200 \mathrm{~mL} \cdot \mathrm{min}^{-1}$. Each sample was run in three replicates. In the same conditions, different water traps were connected to the inlet of the combination sorbent tubes (Tenax-Carboxen) to study their suitability.

\section{Sample recuperation by thermal desorption, separation and identification}

For the sample recovery test, a mixture of acetone, ethanethiol, triethyamine and hexane was prepared. The concentration of each compound was $0.1 \mathrm{mg} \cdot \mathrm{m}^{-3}$ and sampling was carried out for $5 \mathrm{~min}$ at $150 \mathrm{~mL} \cdot \mathrm{min}^{-1}$.

Analysis were carried out with a Perkin Elmer device configured as follows : an automatic thermal desorber model ATD 400 was coupled with an autosystem gas chromatograph (GC) and a mass spectrometer (MS) Q-mass model.

Typical thermal desorption was carried out in two step by heating at $250{ }^{\circ} \mathrm{C}$ for $5 \mathrm{~min}$ the sample tube with helium at a gas flow rate of $20 \mathrm{~mL} \cdot \mathrm{min}^{-1}$. Desorbed organic compounds were then trapped again without splitting into an internal cold trap packed with Tenax TA $(40 \mathrm{mg})$ and maintained at $-30{ }^{\circ} \mathrm{C}$ by Peltier effect. This new trap was then heated quickly to $250{ }^{\circ} \mathrm{C}$ at $40{ }^{\circ} \mathrm{C} . \mathrm{s}^{-1}$ and the volatiles were injected in the chromatographic system via a transfer line at $200{ }^{\circ} \mathrm{C}$ and with a $10: 1$ split ratio.

These conditions were chosen after thermal desorption tests of a mixture of acetone, ethanethiol, triethylamine and hexane on a Tenax TA-Carboxen 564 tube. These experiments were carried out with different flow rates, temperatures and desorption times.

The separation was performed by using a SGE $50 \mathrm{~m} \times 0.32 \mathrm{~mm}$-i.d., $3 \mu \mathrm{m}$ film BPX-5 column (apolar stationary phase) with an helium flow fixed at $1 \mathrm{~mL} \cdot \mathrm{min}^{-1}$. The oven was initially set at $35{ }^{\circ} \mathrm{C}$ for $5 \mathrm{~min}$ and programmed to $300{ }^{\circ} \mathrm{C}$ at $10{ }^{\circ} \mathrm{C} \cdot \mathrm{min}^{-1}$.

The quadripolar mass detector was linked with the GC by a transfer line maintained at $220{ }^{\circ} \mathrm{C}$. Mass spectra were obtained by full scan electronic impact mode. The electron energy was set to $70 \mathrm{eV}$, the electron multiplier to $1150 \mathrm{mV}$, the ion source temperature to $220{ }^{\circ} \mathrm{C}$ and the mass range was from 12 to 261 a.m.u. collecting two scans per second. Using a PC-486 computer and the NIST library of the software respectively performed data collection and spectra indication.

\section{Results}

\section{Independent influence of operating conditions on sampling and breakthrough volume}

In order to find the best conditions to concentrate odorous compounds, the influence of several factors such as sampling flow, temperature and concentration were estimated.

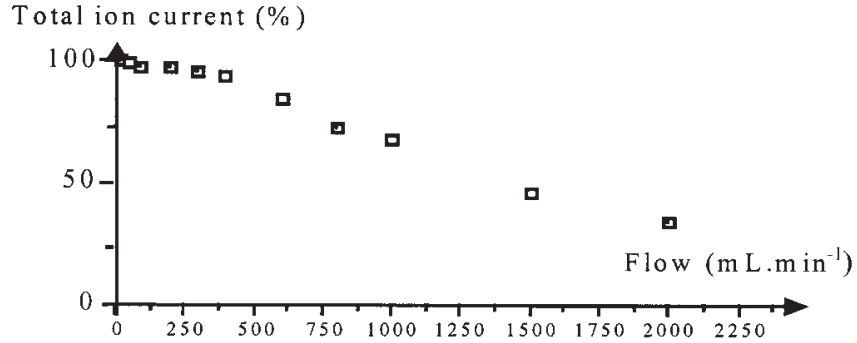

Figure 3. Influence of sampling flow rate on ATD/GC/MS analysis of two litres of an atmosphere at $0.1 \mathrm{mg} \cdot \mathrm{m}^{-3}$ of acetone (temperature $25^{\circ} \mathrm{C}$ ).

\section{Influence of flow rate on quantitative sampling}

Results, shown on figure 3, indicate that signal and therefore the quantity of acetone is constant when the sampling flow is maintained lower than $250 \mathrm{~mL} \cdot \mathrm{min}^{-1}$. By increasing this flow at values higher than $400 \mathrm{~mL} \cdot \mathrm{min}^{-1}$, the adsorption decrease quickly and resulting analysis could be not quantitative.

Such a limit on flow is confirmed by velocity through the sorbent bed. The maximal velocity, $\mathrm{B}_{\max }$, must do not exceed $500 \mathrm{~cm} \cdot \mathrm{min}^{-1}$ [15]. According to the characteristics of the cartridge $(0.4 \mathrm{~cm}-\mathrm{i} . \mathrm{d}$.$) , the sampling flow is limited at$ $250 \mathrm{~mL} \cdot \mathrm{min}^{-1}$ when the following equation 1 is applied.

$$
\left.\mathrm{F}_{\max }=\mathrm{B}_{\max } \pi \text { (i.d.) }\right)^{2} / 4
$$

with $\mathrm{F}_{\max }$ : maximal adsorption flow $\left(\mathrm{mL} \cdot \mathrm{min}^{-1}\right)$

$\mathrm{B}_{\max }$ : maximal velocity $\left(\mathrm{cm} \cdot \mathrm{min}^{-1}\right)$

i.d.: internal diameter of the cartridge $(\mathrm{cm})$

\section{Influence of temperature on breakthrough volume}

Breakthrough volumes (BV) of three gaseous mixtures are presented in figure 4 . These results confirm that temperature has a strong effect on adsorption capacity. Whatever the gas, the capacity decreases with temperature increasing and follow the relation $\log (\mathrm{BV})=f\left(10^{3} / \mathrm{T}\right)$. At low temperatures $\left(20-40{ }^{\circ} \mathrm{C}\right)$, the evolution is important and the limits were found around $70{ }^{\circ} \mathrm{C}$.

Oxygenated and nitrogenated compounds are well trapped on chosen sorbents. Even if sulphur compounds are not trapped in similar amounts, these compounds can also be concentrate because the sampling of large volumes (higher than $10 \mathrm{~L}$ ) of an atmosphere, at $0.5 \mathrm{mg} \cdot \mathrm{m}^{-3}$ concentration, are allowed if temperature do not exceed $40{ }^{\circ} \mathrm{C}$. So the behaviour of chosen sorbents seems to be acceptable and their adsorption capacity is good enough. But, in order to be sure of sample integrity, it is better to use two cartridges, the first one for analysis and the second to control that breakthrough was not obtain.

\section{Influence of concentration on breakthrough volume}

Values of breakthrough volumes on Tenax TA/ Carboxen 564, with different concentrations, are presented 


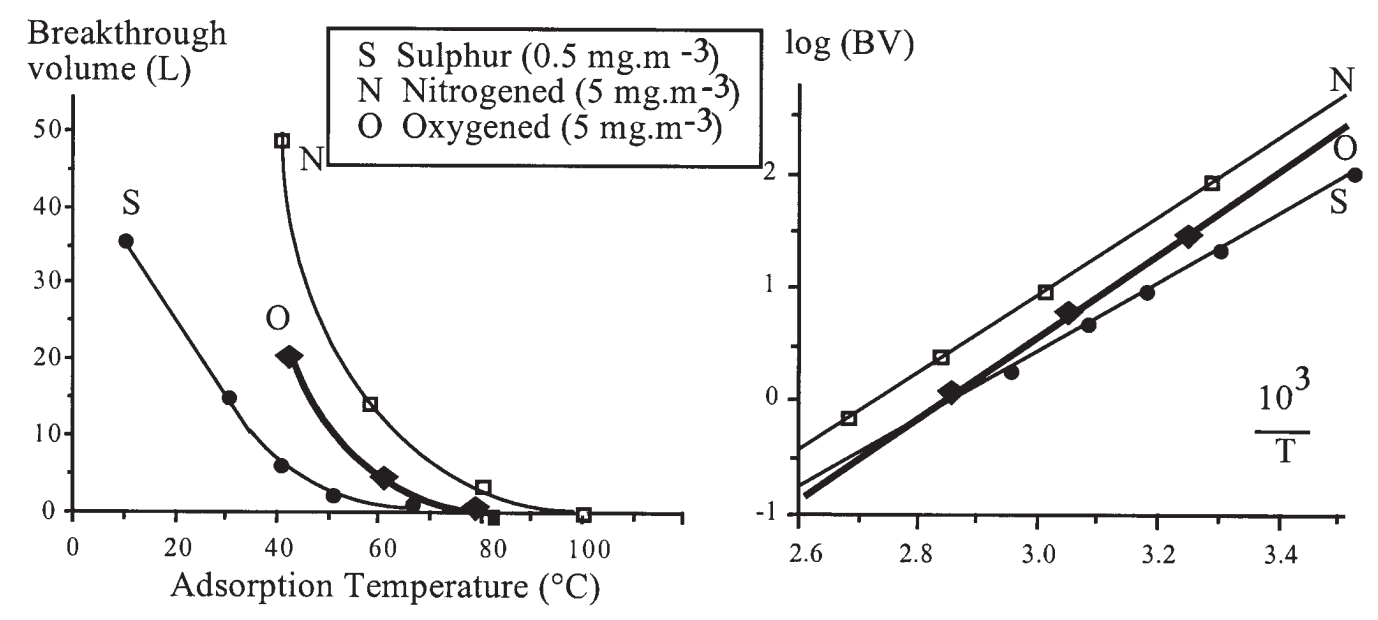

Figure 4. Evolution of breakthrough volume (BV), for each odorous family, with the temperature.
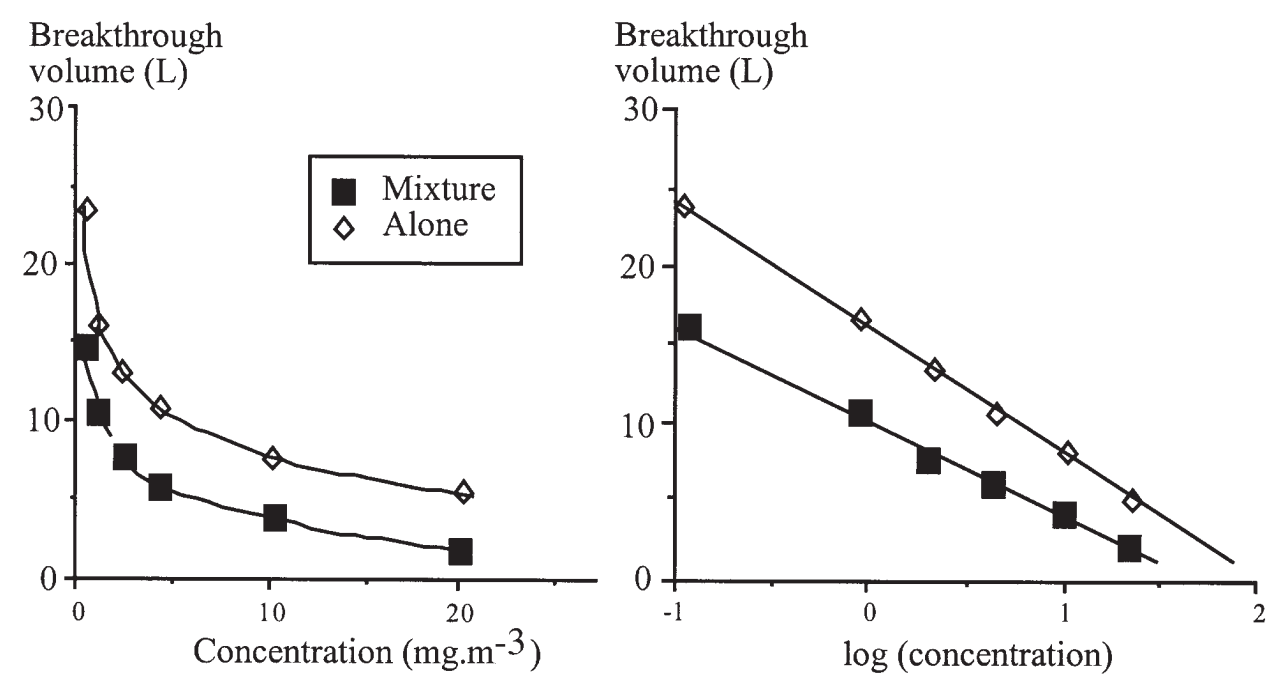

Figure 5. Comparison between breakthrough volumes of dimethylsuphide alone or in an equimolar mixture of five compounds.

in table IV and figure 5. Dimethylsulphide is eluted first, so the mixture breakthrough value depends on this compound. Of course, the adsorption capacity of the support can be better is this compound is not in a complex mixture, without competition for sorption sites. These results show that

Table IV. Breakthrough volume of the mixture with various concentrations.

\section{Average concentration of}

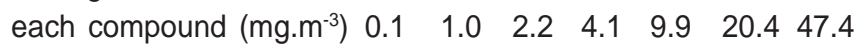

Breakthrough volume

of the mixture $(L)$

$\begin{array}{llllll}16.1 & 10.7 & 7.8 & 6.0 & 4.0 & 2.0<0.5\end{array}$ adsorption capacity of two-layer sorption tube is sufficient because for concentrations lower than $1 \mathrm{mg} \cdot \mathrm{m}^{-3}$, sampling volume can be higher than $10 \mathrm{~L}$. With such a sampling volume, limit of detection can be between 1 to $10 \mu \mathrm{g} \cdot \mathrm{m}^{-3}$.

As shown in figure 5, the adsorption capacity decrease when gas concentration increase with a logarithmic relation as $\mathrm{BV}=f(\log \mathrm{C})$.

\section{Combined influence of flow rate, temperature and concentration}

Results are presented in table V. The experimental amount of adsorbed part $\left(\mathrm{M}_{\exp }\right)$ after breakthrough is calculated with the relation 2 . 
Table V. Experimental matrix and results.

\begin{tabular}{lccrr}
\hline $\begin{array}{c}\text { Concentration } \\
\left(\mu g . L^{-1}\right)\end{array}$ & $\begin{array}{c}\text { Temperature } \\
\left({ }^{\circ} \mathrm{C}\right)\end{array}$ & $\begin{array}{c}\text { Flow } \\
\left(\text { L.min }^{-1}\right)\end{array}$ & $\begin{array}{c}t_{B} \\
(\mathrm{~min})\end{array}$ & $\begin{array}{r}M_{\exp } \\
(\mu \mathrm{g})\end{array}$ \\
\hline 0.5 & 10 & 0.1 & 395 & 19.8 \\
5 & 10 & 0.1 & 120 & 60.0 \\
0.5 & 30 & 0.1 & 150 & 7.5 \\
5 & 30 & 0.1 & 43 & 21.5 \\
0.5 & 10 & 0.2 & 190 & 19.0 \\
5 & 10 & 0.2 & 58 & 58.0 \\
0.5 & 30 & 0.2 & 74 & 7.4 \\
5 & 30 & 0.2 & 21 & 21.0 \\
\hline
\end{tabular}

$$
\mathrm{M}_{\text {exp }}=\mathrm{t}_{\mathrm{B}} \cdot \mathrm{F} \cdot \mathrm{C}
$$

with $t_{B}$ : time for breakthrough (min)

$\mathrm{F}$ : adsorption flow (L. $\left.\mathrm{min}^{-1}\right)$

$\mathrm{C}$ : concentration $\left(\mu \mathrm{g} . \mathrm{L}^{-1}\right)$

With these results, a modelling, based on second order polynomial model (equation 3), can be proposed.

$t_{B}=b_{0}+b_{f} F+b_{t} T+b_{c} C+b_{f t} F \cdot T+b_{f c} F \cdot C+b_{t c}$ T.C

with $b_{0} \quad$ average response in experimental field,

$b_{f}, b_{t}, b_{c}$ coefficients corresponding to the effects of the factors (flow rate, temperature and concentration respectively),

$b_{\mathrm{ft}}, \mathrm{b}_{\mathrm{fc}}, \mathrm{b}_{\mathrm{tc}}$ coefficients corresponding to the influence of interaction between two factors.

Calculation of these coefficients leads to the values reported in table VI. A coefficient is considered significant when its probability to have an influence is higher than $95 \%$. A coefficient $b_{\text {ftc }}$, corresponding to the interaction of the three factors and which implies a third order equation, was not taken in account in the model and low signification of two-terms interactions proves that a three-terms interaction will be negligible.

High values for $b_{c}$ and $b_{t}$ indicate the main influence of temperature and concentration on adsorbed amount. The sign of these two coefficients are different showing that increase

Table VI. Coefficients and signification.

\begin{tabular}{crr}
\hline Coefficient & Value & Signification \\
\hline $\mathrm{b}_{0}$ & 26.775 & $>99.0 \%$ \\
$\mathrm{~b}_{\mathrm{c}}$ & 13.350 & $>99.0 \%$ \\
$\mathrm{~b}_{\mathrm{t}}$ & -12.425 & $>99.0 \%$ \\
$\mathrm{~b}_{\mathrm{f}}$ & -0.425 & $84.6 \%$ \\
$\mathrm{~b}_{\mathrm{ft}}$ & -6.450 & $>95.0 \%$ \\
$\mathrm{bfc}$ & -0.200 & $69.8 \%$ \\
$\mathrm{~b}_{\mathrm{tc}}$ & 0.275 & $76.9 \%$ \\
\hline
\end{tabular}

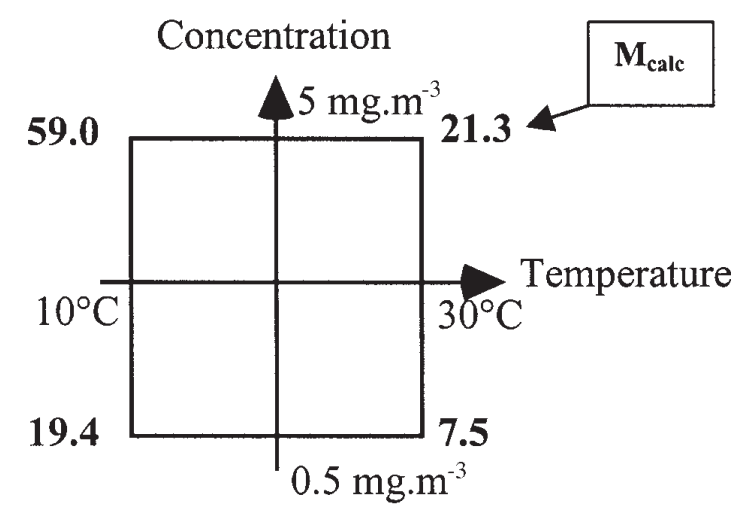

Figure 6. Interaction between concentration and temperature on calculated response Mcalc (flow rate fixed at $150 \mathrm{~mL}^{\mathrm{min}}{ }^{-1}$, average value on experimental field).

of concentration has a positive effect on adsorption while increase of temperature limits the phenomenon. The adsorbed amount can increase as a function of concentration even if in the same time the breakthrough volume decrease. This behaviour can be explained by the adsorption equilibrium between gas phase and sorbent. Sampling flow between 100 and $200 \mathrm{~mL} \cdot \mathrm{min}^{-1}$ has no influence on adsorption. Excepted the interaction between the two main factors (temperature and concentration) represented in figure 6 , the interactions are very low.

Looking at these results, it is recommended to develop sampling on Tenax TA-Carboxen 564, at a flow rate around $150 \mathrm{~mL} \cdot \mathrm{min}^{-1}$ and at low temperature in order to increase adsorption capacity. The concentration is generally unknown at the sampling step, then several samples with different volumes of loaded air have to be performed.

\section{Modification of adsorption with humidity}

The experiments were realized with saturated supports. This saturation was confirmed by the analysis of a second tube placed after the first one. The comparison is therefore based on maximal adsorption capacity and depends on adsorbent and humidity level. Chromatographic areas obtained by ATD/GC/MS analysis are shown in figure 7.

These results show that water traces are present with both sorbents even if Tenax TA and Carboxen 564 are considered as hydrophobic supports. When humidity level is lower than $90 \%$ r.h., water trapping is low and does not affect chromatographic resolution. On the contrary, with high level of humidity (> $90 \%$ r.h.), the amount of trapped water is important especially on molecular sieve. In this last case, water interacts with first eluted compounds during chromatographic separation and can also affect mass detection. High humidity is responsible of competition on Carboxen 564 adsorption sites because the capacity of the molecular sieve decreases about $25 \%$ for acetone, ethanethiol and triethylamine. With polymer Tenax TA, 


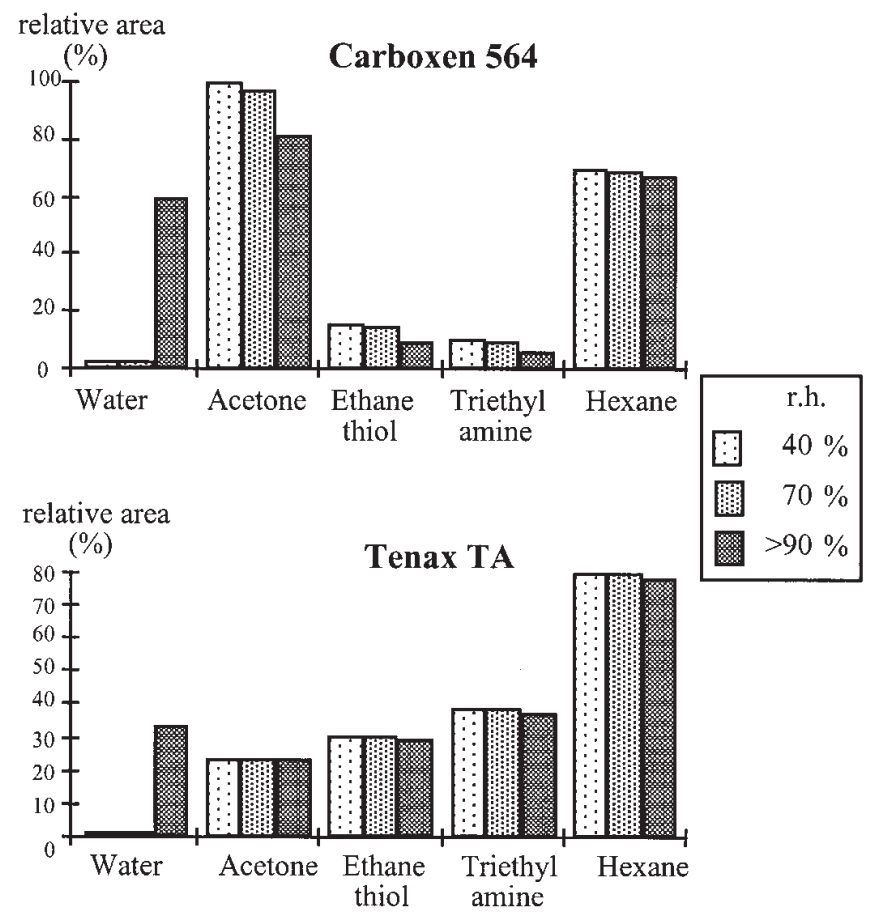

Figure 7. Desorbed compounds after sampling in different relative humidity atmospheres (relative areas are given looking at area of acetone on Carboxen 564 with $40 \%$ r.h.).

humidity do not change capacities but if the atmosphere is $>90 \%$ r.h., textural modification of the polymer is observed (polymer expanding in the tube).

The different behaviour between the two supports can be explained by the different structures: an organic polymer and a carbon molecular sieve. Tenax TA and Carboxen 564 have been designed for trapping of volatile $\left(>\mathrm{C}_{4}\right)$ or semi-volatile organic compounds (3) and smaller organic analytes respectively. Water is more retained on Carboxen 564 than on
Tenax TA. With high moisture level, Tenax TA, which is less selective than the carbon molecular sieve, offer greater sample representativity.

\section{Test to remove humidity before the sampling step}

In order to avoid the perturbation due to moisture, experiments to trap water first were carried out with several salts as dryers or a cold trap at $0{ }^{\circ} \mathrm{C}$. Characteristics of drying agents, such as ability to retain water and their re-usability after heating were tested before the experiments. These drying agents confirm their good desiccant behaviour.

An experiment, at $40 \%$ r.h., without drying step is presented as reference and others involving drying step are shown in table VII. With the cold trap, after sampling, considerable amounts of liquid water remained in the coil. To desiccate the moist gas stream, this trap provided for the condensation of water because no water pick appeared on the corresponding chromatograms. But there were significant losses of compounds. Volatile analytes might be partially condensed in the cold trap water. Therefore such a trap is not ideally suited for use before the trapping of volatile organic compounds.

The main problem in water removal from an effluent is the losses of volatile analytes that will occur. When drying columns were filled with calcium chloride or magnesium sulphate, considerable losses of compounds were noted, which rendered these agents not suitable. On the contrary, sodium carbonate presented good behaviour with the low and high r.h.: the recoveries of acetone, ethanethiol and hexane on sample tubes were optimum (>90\%). However, substantial losses were observed with triethylamine (critical recoveries of $75 \%$ ). The $\mathrm{GC}$ chromatograms profile obtained with the $\mathrm{Na}_{2} \mathrm{CO}_{3}$ drying agent appeared satisfactory.

\section{Sample recuperation by thermal desorption}

Results, given in table VIII, show that the primary thermal desorption of the selected compounds, from a cartridge Tenax TA/Carboxen 564, can be easily quantitative. The

Table VII. Recuperated compounds after desorption of Tenax TA-Carboxen 564 cartridges preceded by different dryers.

\begin{tabular}{|c|c|c|c|c|c|}
\hline & $\begin{array}{l}\text { Relative } \\
\text { humidity }\end{array}$ & $\begin{array}{c}\text { Acetone } \\
\text { (\%) }\end{array}$ & $\begin{array}{c}\text { Ethanethiol } \\
(\%)\end{array}$ & $\begin{array}{c}\text { Hexane } \\
\text { (\%) }\end{array}$ & $\begin{array}{c}\text { Triethylamine } \\
\text { (\%) }\end{array}$ \\
\hline Without dryers & $40 \%$ & 100 & 100 & 100 & 100 \\
\hline Cold trap & $>90 \%$ & 43 & 19 & 77 & $<5$ \\
\hline \multirow[t]{2}{*}{$\mathrm{CaCl}_{2}$} & $40 \%$ & 0 & 42 & 50 & 0 \\
\hline & $>90 \%$ & 0 & 5 & 5 & 0 \\
\hline \multirow[t]{2}{*}{$\mathrm{MgSO}_{4}$} & $40 \%$ & 0 & 5 & 31 & 0 \\
\hline & $>90 \%$ & 0 & 8 & 15 & 0 \\
\hline \multirow[t]{2}{*}{$\mathrm{Na}_{2} \mathrm{CO}_{3}$} & $40 \%$ & 98 & 94 & 99 & 80 \\
\hline & $>90 \%$ & 95 & 91 & 92 & 72 \\
\hline
\end{tabular}


Table VIII. Thermal desorption yield depending on flow rate, temperature and desorption time.

\begin{tabular}{|c|c|c|c|c|c|c|}
\hline \multirow[b]{2}{*}{$\begin{array}{c}F \\
\left(m L . m i^{-1}\right)\end{array}$} & \multirow[b]{2}{*}{$\begin{array}{c}T \\
\left({ }^{\circ} \mathrm{C}\right)\end{array}$} & \multirow[b]{2}{*}{$\begin{array}{c}t \\
(\min )\end{array}$} & \multicolumn{4}{|c|}{ Yield (\%) } \\
\hline & & & Acetone & Ethanethiol & Triethylamine & Hexane \\
\hline 10 & 100 & 1 & 31.3 & 75.5 & 15.5 & 13.8 \\
\hline 10 & 150 & 5 & 70.0 & 99.7 & 78.6 & 60.6 \\
\hline 20 & 150 & 5 & 78.9 & 99.8 & 82.2 & 69.9 \\
\hline 40 & 150 & 5 & 83.5 & 100.0 & 88.8 & 80.3 \\
\hline 20 & 200 & 5 & 99.8 & 100.0 & 99.2 & 97.0 \\
\hline 20 & 250 & 5 & 100.0 & 100.0 & 99.7 & 100.0 \\
\hline 40 & 250 & 5 & 100.0 & 100.0 & 100.0 & 100.0 \\
\hline
\end{tabular}

temperature and the desorption flow are very important to obtain a good yield. When the temperature is lower than $200{ }^{\circ} \mathrm{C}$, desorption is not complete so this factor must be maintained at $250{ }^{\circ} \mathrm{C}$.

\section{Conclusion}

One of the main problems in sampling malodorous atmospheres is to find the better adsorbent to concentrate molecules at very low levels. Generally, commercial adsorbents present a sufficient concentration capacity to perform analysis. But the choice of this sorbent must be done taking into account several sampling parameters but also recuperation parameters. This study has shown that breakthrough values allowed using the sorbents quite easily when just one compound must be concentrated. With complex organic mixtures, sorbents can be used carefully controlling that breakthrough was not obtain for one component. Other parameters like sampling flow or temperature, which can affect adsorption, are quite easy to control and must be preferentially maintained around $150 \mathrm{~mL} \cdot \mathrm{min}^{-1}$ and $20{ }^{\circ} \mathrm{C}$ respectively. A two bed sorbent tube with Tenax TA and Carboxen 564 seems to be efficient for a wide range of odorous compounds. The remaining problem is the presence of high relative humidity. The present work confirms that significant adsorption of water on Tenax TA and Carboxen 564 occurs. Water trapping appears detrimental for sample recovery on Carboxen only. But in any case that leads to disturbances for GC-MS analysis. Thus, a drying step is necessary to avoid the introduction of water on the solid support. Of the different method tested, sodium carbonate seems to be the material of choice for pretrapping water when sampling odorous compounds mixture with high relative humidity. Possible interactions of the drying agent with the standard compounds have been checked and only partial adsorption of the triethylamine was observed.

\section{Acknowledgments}

The authors wish to acknowledge the "Agence de l'Environnement et de la Maîtrise de l'Énergie (ADEME)" for financial support concerning the development of odorous compounds physico-chemical analysis.

\section{Références}

1. Le Cloirec, P.; Fanlo J.-L.; Degorce-Dumas, J.-R. Traitement des odeurs et désodorisation industrielle; Paris: Innovation 128 Ed., 1991.

2. Guillot, J.-M.; Jacob, V.; Laffond, M.; Foster, P. In : Les composés organiques volatils (COV) dans l'environnement; coordonnateur : Le Cloirec P., Paris: Lavoisier Tech. \& Doc. 1998, pp 187-264.

3. Brown, R.H.; Purnell, C.J. J. Chromatogr. 1979, 178, 79-90.

4. Pellizzari, E.D.; Bunch, J.E.; Carpenter, B.H. Environ. Sci. Technol. 1975, 9, 552-555.

5. Kern, H.; Almasi, E.; Kirshen, N. In : Proceedings of the International Conference on V.O.Cs in the Environment; London, 1993, 295-300.

6. Barnes, R.D.; Law, L.M.; MacLeod, A.J. Analyst 1981, 106, 412-418.

7. Hastenteufel, S.; Betz, W.R. In : Clean air at work: new trends in assessment and measurement for the 1990's, Brown, R. H.; Curtis, M.; Saunders K. J. Eds., London: Royal. Soc. of Chemistry, 1992, 190-194.

8. Bertoni, G.; Bruner, F.; Liberti, A.; Perrino, C. J. Chromatogr. 1981, 203, 263-270.

9. Harper, M. In : Proceedings of the International Conference on V.O.Cs in the Environment; London, 1993, 349-359.

10. Tangerman, A. J. Chromatogr. 1986, 366, 205-216.

11. Ambrus, A.; Thier, H.P. Pure Appl. Chem. 1986, 58, 1035.

12. Mc Clenny ,W.A.; Oliver, K.D.; Pleil, J.D. Environ. Sci. Technol. 1989, 23, 1373-1379.

13. Juttner, F. J. Chromatogr. 1988, 442, 157-163.

14. Sado, G.; Sado, M.C. In : Les Plans d'expériences : De l'instrumentation à l'assurance qualité; Paris: Afnor, 1991.

15. Pellizzari, E.D. In : Organic chemistry of the atmosphere, New York: Ann Arbor Science Publishers, 1991. 